\title{
February-May temperature reconstruction based on tree-ring widths of Abies fargesii from the Shennongjia area in central China
}

\author{
Yonghong Zheng ${ }^{1} \cdot$ Xuemei Shao ${ }^{2} \cdot$ Fei $\mathrm{Lu}^{3} \cdot{\operatorname{Yan~} \mathrm{Li}^{4}}^{4}$
}

Received: 3 February 2015 / Revised: 26 October 2015 / Accepted: 9 November 2015 / Published online: 13 January 2016

(C) ISB 2016

\begin{abstract}
February-May temperature strongly affects ecological processes and socio-economics in central China, yet its long-term variability has not been thoroughly assessed due to the shortness of instrumental records. In order to improve the understanding of the regularities of temperature variability in central China, in this study, we present a new tree-ring chronology from the Shengnongjia Mountains in central China which provides a valuable 245-year record of temperature variability. The reconstructed temperature correlated strongly with February-May mean temperature records of the Fangxian meteorological station from AD 1958 to AD 2011, and the derived reconstruction explained $44.5 \%$ of the instrumental temperature variation during this period. The study shows that this region experienced three warm periods and two cool periods, i.e., the major warm periods occurred in AD 1783-1806, AD 1879-1909, and AD 1975 to the present, whereas the cool intervals occurred in AD 1807-1878 and AD 1910-1974. This reconstruction could aid in the evaluation of regional climate variability in subtropical China.
\end{abstract}

Keywords Shengnonjia $\cdot$ Central China .

Dendroclimatology $\cdot$ A. fargesii $\cdot$ Temperature reconstruction

Yonghong Zheng

zhengyh@whu.edu.cn

1 School of Resource and Environmental Sciences, Wuhan University, Wuhan 430079, China

2 Institute of Geographic Sciences and Natural Resources Research, Chinese Academy of Sciences, Beijing 100101, China

3 Hebei Provincial Environmental Scientific Research, Shijiazhuang 050037, China

4 Meteorological Observation Center of CMA, Beijing 10086, China

\section{Introduction}

Long-term climate data not only can help us understand the past climate changes, such as extreme events and abrupt changes, but also can provide, together with historical documents, tools to understand how climate has affected ecological processes and socio-economics in the past. Although there is an increasing number of dendroclimate reconstructions of past climates on regional to global scales (Cook et al. 2013; Ljungqvist 2010; Moberg et al. 2005), more effort should be made due to the climate change has a strong regional expression. In the past two decades, great progress has been made in tree-ring temperature reconstruction studies in China, especially on the Qinghai-Tibet Plateau (Zhu et al. 2011; Liu et al. 2009; Deng et al. 2014; Yang et al. 2014; Shao et al. 2010). In contrast, only a few tree-ring climate reconstruction studies have been conducted in subtropical China (Zheng et al. 2012; Chen et al. 2012; Duan et al. 2011; Shi et al. 2010) due to the scarcity of old-growth forests and the complexity of the relationship between tree growth and climate in this region, just so limits the understanding of past climate changes in subtropical China before the instrumental record.

Abies fargesii, which is endemic to central China, is widely distributed in the Qinba Mountains of China. It generally grows within an altitudinal range of 2000 to $3100 \mathrm{~m}$ and dominates the forests above $2500 \mathrm{~m}$ a.s.l. in the Shennongjia Mountains ( $\mathrm{Li}$ 1991), which is not only a treasure house of biodiversity in China but also a green ecological protective screen for the world-famous "three gorges reservoir" area. Several dendroecological studies conducted in the Shennongjia area showed that $A$. fargesii is valuable for dendroclimate research (Dang et al. 2013b; Dang et al. 2013a). However, so far, it has no tree-ring-based climate records exceeding 200 years in this region. We were lucky to found that there were many old trees of $A$. fargesii in our 
preliminary investigation in 2011, which provided opportunities to conduct dendroclimate reconstruction research in this region. So, the important issue that concerned in this study is whether the climate signal embedded in ring widths of A. fargesii can be extracted successfully and improves the understanding of the regularities of temperature variability in warm and humid subtropical China.

In this study, we developed a 245 -years tree-ring width chronology using tree-ring cores from $A$. fargesii in the Shennongjia area. The growth-climate relationship was then analyzed, and lastly, the temperature variations from AD 1767 to AD 2011 were reconstructed. The study was the first treering-based temperature record exceeding 200 years in the Shennongjia area. The reconstruction could be useful in better understanding the characteristics of climate variation in the study area over the past two centuries.

\section{Materials and methods}

\section{Study area}

The Shennongjia area $\left(31^{\circ} 15^{\prime}-31^{\circ} 57^{\prime} \mathrm{N}, 109^{\circ} 55.8^{\prime}-110^{\circ}\right.$ $58.2^{\prime} \mathrm{E}$ ), located in western Hubei Province in central China, has a total area of $3253 \mathrm{~km}^{2}$ (Fig. 1). According to the division of Chinese geomorphological units, it belongs to the second terrace of the Chinese continent, lying from east to west in the eastern part of the Daba Mountains, and forms a watershed between the Hanjiang River and the Yangtze River (the third longest river in the world). Most of the peaks of the Shennongjia Mountains are higher than $1500 \mathrm{~m}$ a.s.l., with the highest peak (Mt. Shennongjia) at $3105 \mathrm{~m}$ a.s.l. There are 3479 higher plants (with the exception of Bryophyta), belonging to 1010 genera and 201 families. The vertical vegetation distribution on Mt. Shennongjia is very distinct from low to high elevations, varying from evergreen broadleaved forest, followed by evergreen and deciduous broadleaved forest, deciduous broadleaved forest, conifer and deciduous broadleaved forest, and sub-alpine conifer forest (including sub-alpine shrubs and meadows) (Zhao et al. 2005)..

The climate in the Shennongjia area is typical of subtropical mountains, with mild, wet summers and cold, dry winters owing to its location in the transitional zone between the northern subtropical zone and the warm temperate zone. According to the 30-year (AD 1981-2010) climate records of the Shennongjia meteorological station, the mean annual precipitation is $950.9 \mathrm{~mm}$, and approximately $71 \%$ falls between May and September, with the monthly mean temperatures ranging from $0.9{ }^{\circ} \mathrm{C}$ in January to $22.8{ }^{\circ} \mathrm{C}$ in July. Besides this, the precipitation increases, and the temperature decreases with increasing altitude in this mountainous region.

\section{Climate data}

There are three national principal meteorological stations close to the sampling sites: the Fengjie meteorological station $\left(31^{\circ} 1.2^{\prime} \mathrm{N}, 109^{\circ} 31.8^{\prime} \mathrm{E}, 299.8 \mathrm{~m}\right.$ a.s.l.), the Badong meteorological station $\left(31^{\circ} 1.8^{\prime} \mathrm{N}, 110^{\circ} 22.2^{\prime} \mathrm{E}, 334 \mathrm{~m}\right.$ a.s.l.), and the Fangxian meteorological station $\left(32^{\circ} 1.8^{\prime} \mathrm{N}, 110^{\circ} 46.2^{\prime} \mathrm{E}\right.$, $426.9 \mathrm{~m}$ a.s.l.). In addition, there is a national meteorological observation station, the Shennongiia meteorological station $\left(31^{\circ} 45^{\prime} \mathrm{N}, 110^{\circ} 40.2^{\prime} \mathrm{E}, 935.2 \mathrm{~m}\right.$ a.s.1.) (Fig. 1). Due to the limited climate records (AD 1975-2011) available from the Shennongjia meteorological station and the relatively large difference in altitude between the Fengjie meteorological station, the Badong meteorological station, and the sampling sites, the climate data (AD 1958-2011) were adopted from the Fangxian meteorological station. The data were obtained from the China Meteorological Data Sharing Service System (http://cdc.nmic.cn/home.do), including the mean monthly maximum temperatures (TMX), the mean monthly temperatures (TMP), the mean monthly minimum temperatures (TMN), and the total monthly precipitation (PRE). Furthermore, gridded climate data (1901-2011), the CRU TS Version 3.22 mean monthly temperature, and monthly precipitation were obtained from the KNMI Climate Explorer (http://climexp.knmi.nl/selectfield_obs2. cgi?id=someone@somewhere).

\section{Field sampling}

Tree-ring samples were collected at two sites approximately $2750 \mathrm{~m}$ a.s.l. in the Shennong peak scenic area of the Shennongjia area in July 2012. All of the largest and presumably oldest trees were selected for increment core sampling at breast height (1.3 m above the ground) parallel to the slope contour via increment borers. In total, 65 increment cores from 27 trees were sampled at $\mathrm{XCP}\left(31^{\circ} 28.8^{\prime} \mathrm{N}, 110^{\circ} 17.4^{\prime} \mathrm{E}\right)$, and 51 increment cores from 25 trees were sampled at $\mathrm{SNG}\left(31^{\circ}\right.$ $25.8^{\prime} \mathrm{N}, 110^{\circ} 16.2^{\prime} \mathrm{E}$ ), with 2 or 3 increment cores sampled from each tree.

\section{Tree-ring chronology development}

In the laboratory of Wuhan University, the increment cores were mounted in slotted wooden boards and polished by a sander with sandpaper of progressively fine grit. After being visually cross-dated (Yamaguchi 1991), the cores were measured to the nearest $0.001 \mathrm{~mm}$ through a LINTAB 6 tree-ring measurement station and the TSAP-Win program (Rinn 2003). The width measurements were checked using the COFECHA software (Holmes 1983). We pooled all samples to develop a single composite ring-width chronology for the study area. If three cores were taken from a tree in which the former two that showed the highest correlation with the master 
Fig. 1 Locations of the sampling sites

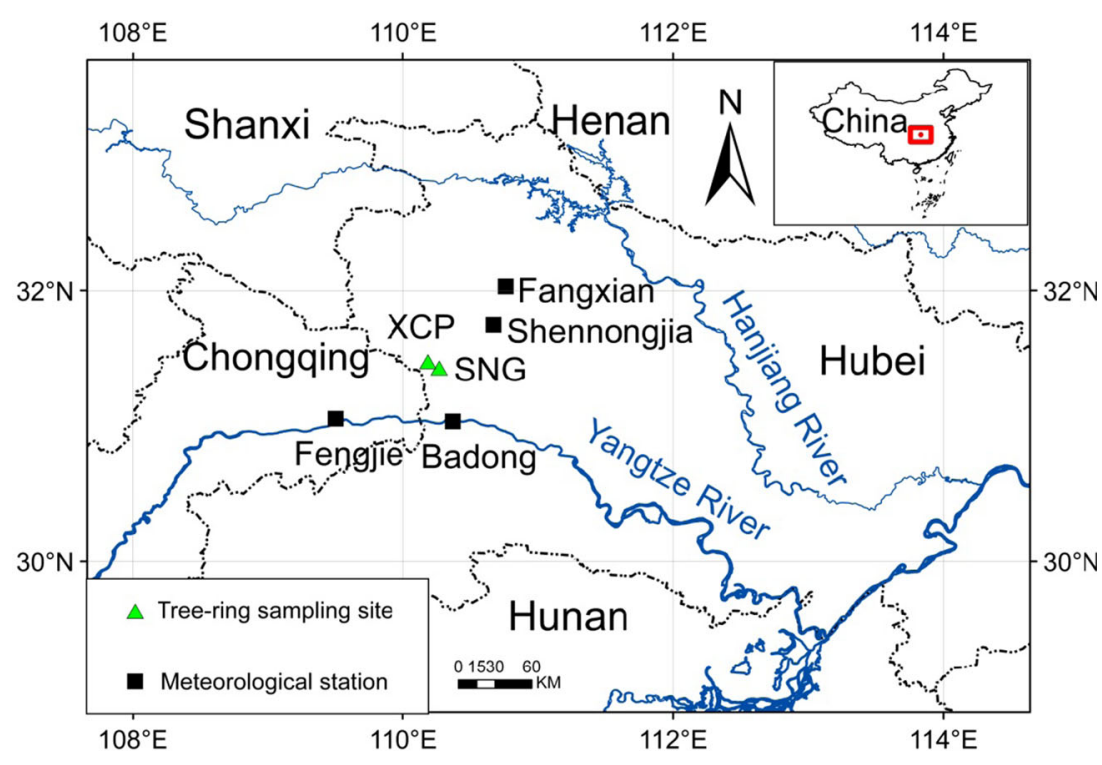

series were included in the final chronology while the other one was removed, cores with poor correlation with the master series were also removed, and 101 increment cores from 52 trees were remained at last. Then, the CRUST software (Melvin and Briffa 2014) was employed to create a standard chronology, smoothing splines with two-thirds of the length of each series with a $50 \%$ amplitude reduction was employed firstly, negative exponential curves or linear regressions with negative or zero slopes were employed secondly, and all the above methods were combined with signal free method (Melvin and Briffa 2008) to model the biological growth trends in the tree-ring width measurements. The quality of chronology was interpreted by the expressed population signal (EPS) statistic. In this study, running EPS and RBAR were calculated using a 30 -year window that lags by 15 years.

\section{Data analysis}

Growth-climate relationships, between the standardized ring width chronology and meteorological records and the CRU TS v3.22, for a common period of AD 1958-2011, were investigated by Pearson's correlation in MATLAB. The meteorological data was tested using 20 months of data from March of the year preceding ring formation to October of the year that ring formation. Based on the results of the correlation analysis, a transfer function between the climate data and the tree-ring chronology during the period AD 1958-2011 was derived. To evaluate the stability of the regression equations, Jackknife and bootstrap (with 500 bootstrap samples) statistical methods (Wu 1986) were performed due to the shortness of the climate period (AD 1958-2011). Statistical parameters were calculated for the regression equation in the calibration and verification period, including the correlation coefficient $(R)$, the coefficient of determination $\left(R^{2}\right)$, the standard error of the estimate (SE), the F-ratio $(F)$, the $\mathrm{t}$ statistic $(t)$, the $p$-value $(P)$, and the Durbin-Watson statistic (DW). The relationship between the observed and reconstructed time series was also tested after removal of low-frequency variation by first differencing. To further understand the regularities of temperature variation, the warm and cool periods were divided on time scale of decades.

\section{Results}

\section{Tree-ring width chronology}

As we can see, tree-ring width chronology, and its sample depth, running RBAR, EPS were shown in Fig. 2. The earliest ring dated to $\mathrm{AD} 1767$, and the relatively reliable period was AD 1783 to AD 2011 according to the principle of EPS value $>0.85$ (Fig. 2). The statistics of the standard ring width chronology (AD 1767-2011) and the results of the period of common interval analysis (AD 1893-2005) were computed based on the detrended data. The chronology exhibited typical autoregressive properties, with first-order autocorrelation coefficients averaging to 0.718 . The values of $\mathrm{R} 1, \mathrm{R} 2$, and $\mathrm{R} 3$ were $0.382,0.670$, and 0.379 , respectively. The statistical values of EPS, SNR, and PC1 were 0.978, 43.93, and $40.5 \%$, respectively. These results indicated that the trees exhibited a common signal which may be associated with the climate of subtropical China.

\section{Tree growth-climate relationship}

Figure 3 showed the correlation between the tree-ring chronology and the climate variables of Fangxian meteorological station. But the correlation with gridded climate data was not 
Fig. 2 a Tree-ring width chronology (thin line), and its sample depth (dotted line), b running $\mathrm{RBAR}$, and $\mathbf{c}$ EPS
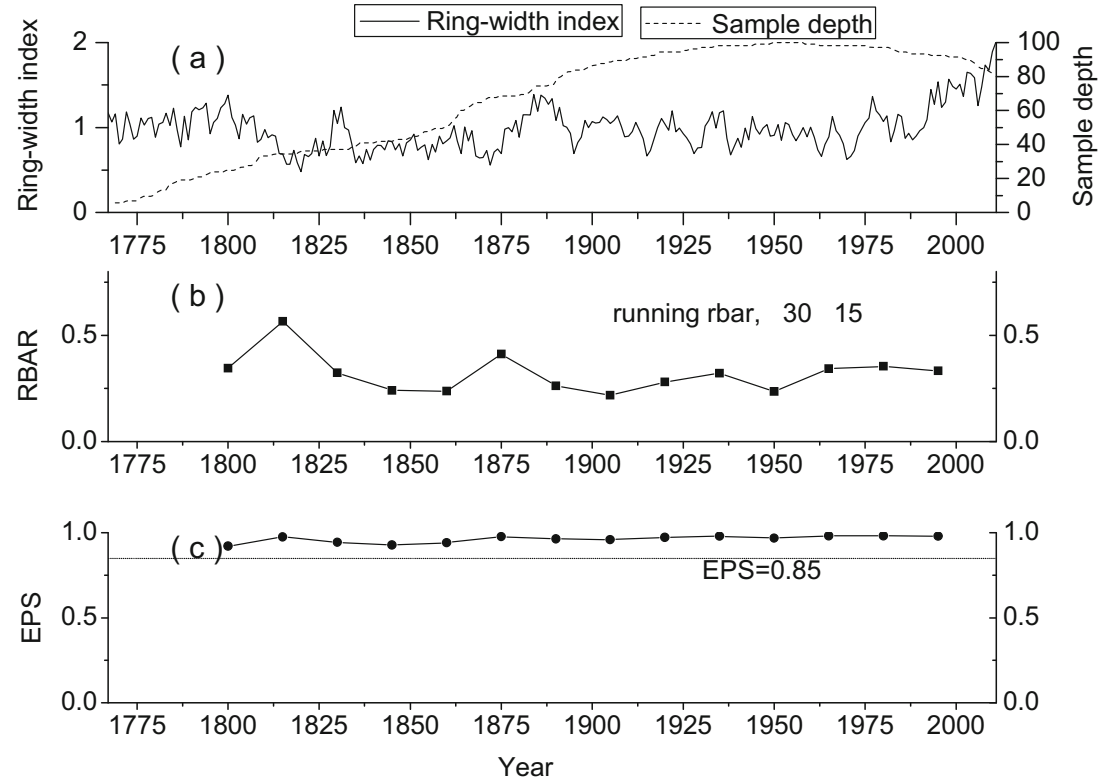

shown due to the relatively lower correlation than with that of meteorological station. Comparisons of the correlation patterns of TMX, TMP, and TMN to the chronology showed that the patterns for these variables were very similar. The months with stronger positive correlations than other months were February, March, and April. The strongest correlation was with the mean temperature in April of the year of ring formation $(r=0.52)$. These results were supported by those obtained from the analysis of relationships of ring width versus mean temperature for A. fargesii in this area (Dang et al. 2013b). However, except for April of the year ring formation, there was far less significant correlation between monthly precipitation and the tree-ring data.

\section{Reconstruction of the February-May mean temperature}

Based on the results as shown in Fig. 3, it seems rational to use February through March or February through April or March through April as the reconstruction period. The final decision to use February through May was based on consideration of the highest correlation with the chronology. After selecting the climatic variable to be reconstructed, we derived a linear regression equation to provide estimates of the values of the February-May mean temperature.

The regression equation derived from the data described above was as follows:

$\mathrm{Y}_{\mathrm{t}}=10.1+1.58 \mathrm{X}_{\mathrm{t}}$

Where $Y_{t}$ is the estimate of the February-May mean temperature (in degrees Celsius) and $\mathrm{X}_{\mathrm{t}}$ is the corresponding treering index value $(\mathrm{t}=$ year in both cases). The reconstruction explained $44.5 \%$ of the temperature variation and $43.4 \%$ after adjustment for the loss of degrees of freedom over the AD 1958-2011 interval.

The reconstruction passed most of the verification tests. The correlation between the observed and reconstructed temperature was $0.667(p<0.001)$. The statistical analysis showed that the sign-test was significant (39 hits, 15 misses), indicating agreement between the observed and reconstructed temperature series from AD 1958 to AD 2011. It is worth noting that the sign-test was not significant at the $5 \%$ level

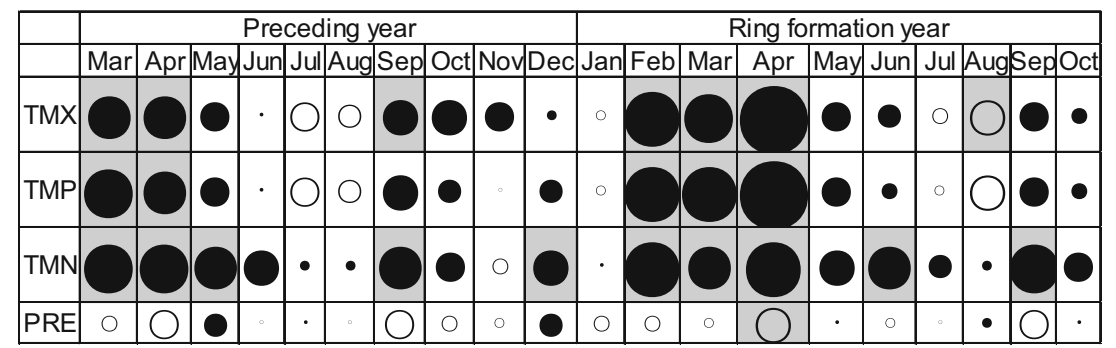

Fig. 3 Correlation between four climate variables and tree-ring chronology. Black circles represent positive correlations and blank for negative. The sizes of the circles indicate the strength of the correlations. A shaded background indicates significance at the level of $\alpha=0.05$ 
after first difference; thus, the low-frequency variability was more obvious than high-frequency variability between the reconstructed and observed temperature data.

As Table 1 listed, statistical parameters of the transfer function, such as $R, R^{2}, F$-value, etc. all showed perfect values. The above statistics demonstrated relatively good predictive capability of the transfer function, and consequently, the February-May mean temperature was reconstructed for the Shennongjia area (Fig. 5a).

The comparison of the observed and reconstructed February-May mean temperature series indicated that there was a strong relationship between the two series (Fig. 4b). The interannual and the 11-year adjacent average of the reconstructed temperature during the last 245 years not only clearly showed the temperature variation but also showed there were several temperature phases (Fig. 5a). If the data were based on the reliable period (1783-2011) long-term average temperature in February-May $\left(11.65^{\circ} \mathrm{C}\right)$, the warm periods include AD 1783-1806, AD 1879-1909, and AD 1975 to the present, and the cool periods include AD 1807-1878 and AD 19101974.

\section{Discussion}

This study confirmed once again that winter-spring temperatures are the critical driving factor of tree radial growth (Fig.3); similar growth response relationships have been reported for Korean pine (Pinus koraiensis) in northeastern China (Zhu et al. 2009), Hinoki cypress (Chamaecyparis obtusa) in central Japan (Yonenobu and Eckstein 2006), pine trees (Pinus massoniana) in southeastern China (Duan et al. 2011), and Shensi fir (Abies chensiensis) in central China (Chen et al. 2015). The above phenomenon may be caused by the photosynthetic "mechanism" that is controlled by the temperature regime, and a higher winter-spring temperature prolongs the period of growth during which the trees are capable of photosynthesis. In contrast, except for the April of the ring formation year, the precipitation in other months seem to have little impact on ring growth because precipitation was not a limiting factor for tree growth in humid regions, especially at high mountainous altitudes in humid regions (Massaccesi et al. 2008). In fact, the significant negative correlation between ring growth and precipitation in April further indicated that temperature was the dominant climatic control factor on ring-width variation of $A$. fargesii. This may be due to the fact that an increase in precipitation could lower the intensity of solar radiation that reaches the earth's surface, thus lowering the temperature. We can also draw the conclusion that the temperature in May has less important than that in February, March, and April to tree radial growth according to the growth-climate response relationship (Fig. 3). This may be owing to the fact that temperature in May has greatly increased leading to the limited effect of temperature on tree growth becoming small.

This chronology captured a significant percentage of the variations in the observed temperature record and appeared to be suitable for reconstructing temperature variability for the subtropical Shennongjia area. This reconstruction showed excellent agreement with the recorded Fangxian mean February-May temperatures (Fig. 4b) and significant correlation $(r=0.405, p<0.001)$ with the CRU TS V3.22 (19012011). To further assess the reliability of this reconstruction, we compared it with temperature reconstructions for Zhenan (Liu and Shao 2000), Qinling Mountain (Chen et al. 2015), Dabie Mountain (Zheng et al. 2012) all in central China, and east Nepal (Cook et al. 2003) (Fig. 5). The pairwise correlation coefficient for their respective common time interval, were $0.309,0.327,0.397$, and 0.340 , respectively. Moreover, February-May temperatures anomaly (1880-2011) based on the Northern Hemisphere Land-Ocean Temperature Index (http://data.giss.nasa.gov/gistemp/tabledata_v3/NH.Ts+ dSST.txt) were also used to compare with our reconstruction; the correlation between them is 0.52 . The above examples confirmed well the reliability of our reconstruction.

It is worth pointing out that the tree-ring chronology was more capable to better capture low-frequency variability than high-frequency variability in temperature. This may be partly resulted from autocorrelation in high-elevation $A$. fargesii due to multi-year needle retention. The temperature signal
Table 1 The statistics of the transfer function and the verification results of the bootstrap and Jackknife methods (Efron 1979)

\begin{tabular}{llll}
\hline & Calibration (1958-2011 AD) & \multicolumn{2}{l}{ Verification (1958-2011 AD) } \\
\cline { 3 - 4 } & & Jackknife mean (range) & Bootstrap (500 iterations) mean (range) \\
\hline$R$ & 0.667 & $0.667(0.65-0.700)$ & $0.670(0.362-0.818)$ \\
$R^{2}$ & 0.445 & $0.445(0.422-0.490)$ & $0.453(0.131-0.670)$ \\
$\mathrm{SE}$ & 0.591 & $0.591(0.572-0.597)$ & $0.577(0.464-0.710)$ \\
$F$ & 41.675 & $40.941(37.306-49.004)$ & $45.754(7.855-105.494)$ \\
$t$ & 34.275 & $33.951(32.168-35.429)$ & $37.597(25.736-44.975)$ \\
$P$ & 0 & 0 & $0(0-0.007)$ \\
DW & 2.009 & $2.006(1.758-2.144)$ & $1.942(1.51-2.02)$
\end{tabular}


Fig. 4 a Scatter diagram of the observed February-May mean temperatures versus the ring width series. b Comparison of the observed and reconstructed February-May mean temperatures

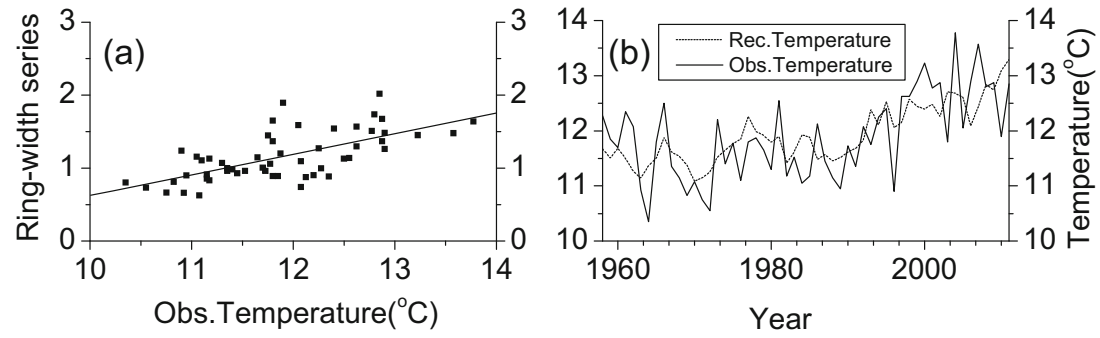

contained in the ring widths was, in effect, naturally smoothed by needle retention, which acted like a biologically imposed low-pass filter (Salzer and Kipfmueller 2005). The study suggested that though the total amount of temperature variation explained by the tree-ring chronology was $44.5 \%$, the lowfrequency decadal-scale variations in temperature were sufficiently well recorded by the tree-ring chronology. Some further works that maybe reveal yearly climate variations, such as the application of tree-ring stable isotope (Au and Tardif 2012) or tree-ring blue intensity (Rydval et al. 2014), should be done in the next step to improve on the current results.

Then, there appeared to be a question: what was the driving mechanism of temperature fluctuations in study area? The reasons might be different in different time. For example, the most prominent warming stage from the late 1980s to present may be related to human activities. While some other period, such as the 1810s, when the great Tambora erupted (Gertisser et al. 2012), may relate to natural causes. When a volcano erupted by throwing out large volumes of sulfur dioxide $\left(\mathrm{SO}_{2}\right)$, water vapor, dust, and ash into the atmosphere, these eruptions could influence climatic patterns for years by increasing planetary reflectivity causing atmospheric cooling. Additionally, as shown in Fig.5, the temperature was not consistent with each other for the 1890 s, which showed regional temperature fluctuation was widespread existence. At the same time, our reconstruction showed more consistency with the northern hemisphere land-ocean temperature than other regional reconstructions (Fig.5) further support the above point of view.

\section{Conclusion}

To conclude, this study reported the results of a tree-ring width data from the Shennongjia area in central China, where highresolution paleotemperature records have heretofore been lacking. A temperature reconstruction was developed that accounted for $44.5 \%$ of the variation in the regional instrumental climate record. This suggested that the tree-ring width of $A$. fargesii was a useful indicator of February-May temperatures in central China. The tree-ring width data provided more information on low-frequency climatic variability than
Fig. 5 Comparison of a February-May temperature reconstructed in this study with $\mathbf{b}$ March-April temperature reconstruction for Zhenan in central China, c February-June temperature reconstruction for the eastern Qinling Mountain in Central China, d February-July temperature reconstruction for Dabie Mountain in central China, e mean February-June temperature reconstruction in east Nepal, and f February-May temperatures anomaly based on the northern hemisphere landocean temperature index. The straight line represents the average temperature
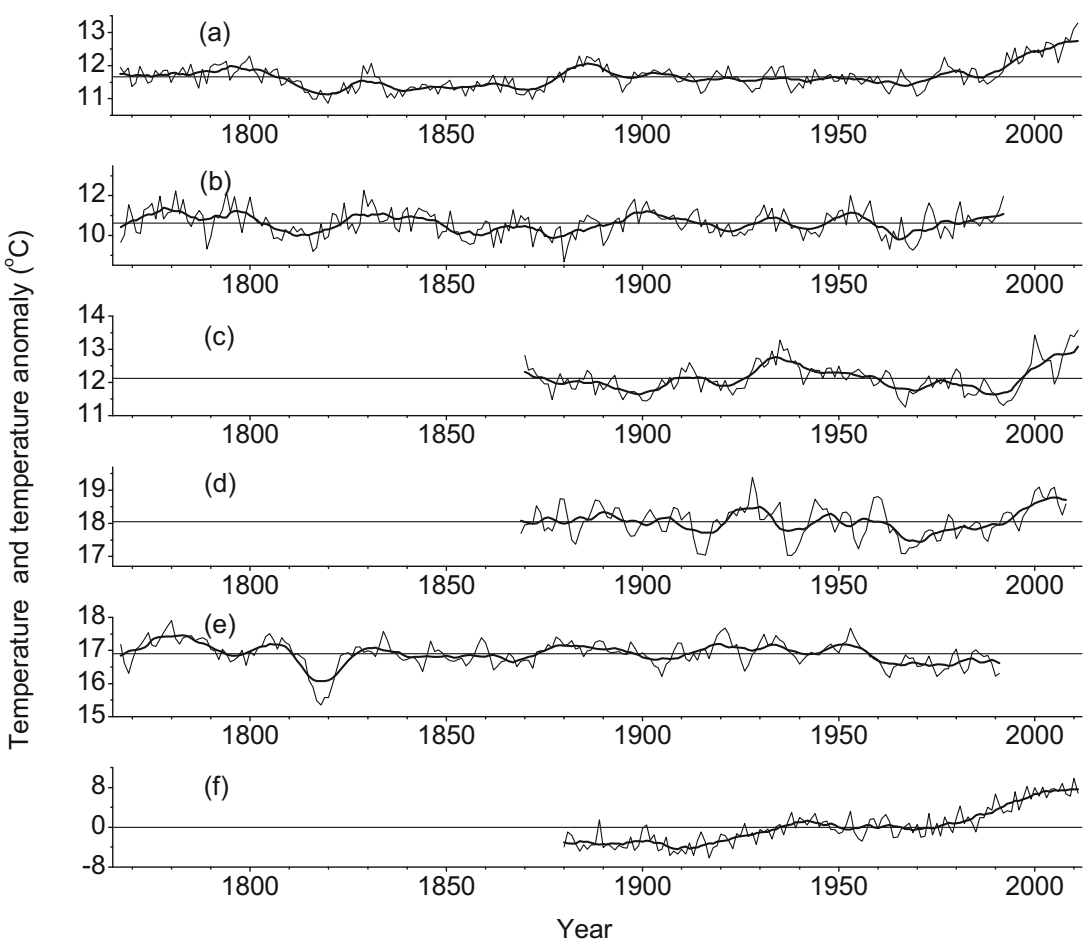
that on high-frequency climatic variability. The reconstruction should be useful, in conjunction with other proxy climate data from the region, such as historical records, in the study of the spatial and temporal extent of climate prior to the observational period. However, because of the relatively warm and humid climate in subtropical China, the rapid metabolism of trees resulted in the phenomenon that there were few trees older than 200 years in the study area; thus, longer dendroclimatic reconstructions require further investigation.

Acknowledgments This work was supported by the National Natural Science Foundation of China (Grant No. 41101186), the Fundamental Research Funds for the Central Universities in China (Grant No. 2042014kf0299). The authors thank Hongbin Liu, Jiangfeng Shi, Danli Li, Peng Xu, Feng Chen, Yiyun Chen, Bo Han, Shengbiao Wu, Haofeng Wang, Jun Zhao, Pin Sun, Yongchao Qi, and Shen Zhao for their great help.

\section{References}

Au R, Tardif JC (2012) Drought signals inferred from ring-width and stable carbon isotope chronologies from Thuja occidentalis trees growing at their northwestern distribution limit, central Canada. Can J For Res 42(3):517-531

Chen F, Yuan YJ, Wei WS, Yu SL, Zhang TW (2012) Reconstructed temperature for Yong'an, Fujian, southeast China: linkages to the Pacific Ocean climate variability. Glob Planet Chang 86-87:11-19

Chen F, R-b Z, Wang H-q, Qin L (2015) Recent climate warming of central China reflected by temperature-sensitive tree growth in the eastern Qinling mountains and its linkages to the Pacific and Atlantic oceans. J Mt Sci 12(2):396-403

Cook ER, Krusic PJ, Anchukaitis KJ, Buckley BM, Nakatsuka T, Sano M (2013) Tree-ring reconstructed summer temperature anomalies for temperate East Asia since 800 CE. Clim Dynam 41(11-12):2957-2972

Cook ER, Krusic PJ, Jones PD (2003) Dendroclimatic signals in long tree-ring chronologies from the Himalayas of Nepal. Int J Climatol 23(7):707-732

Dang H, Zhang K, Zhang Y, Tong X, Zhang Q (2013a) Regeneration dynamics of subalpine fir (Abies fargesii) forest across the altitudinal range in the Shennongjia mountains, central China. J Plant Ecol 6(1):36-47

Dang H, Zhang Y, Zhang K, Jiang M, Zhang Q (2013b) Climate-growth relationships of subalpine fir (abies fargesii) across the altitudinal range in the shennongjia mountains, central China. Clim Chang 117(4):903-917

Deng Y, Gou XH, Gao LL, Yang T, Yang MX (2014) Early-summer temperature variations over the past $563 \mathrm{yr}$ inferred from tree rings in the Shaluli mountains, southeastern Tibet plateau. Quaternary Res 81(3):513-519

Duan JP, Zhang QB, Lv LX, Zhang C (2011) Regional-scale winterspring temperature variability and chilling damage dynamics over the past two centuries in southeastern China. Clim Dynam 39(3-4): 919-928

Efron B (1979) Bootstrap methods: another look at the jackknife. Ann Stat 7(1):1-26

Gertisser R, Self S, Thomas LE, Handley HK, Van Calsteren P, Wolff JA (2012) Processes and timescales of magma genesis and differentiation leading to the great Tambora eruption in 1815. J Petrol 53(2): 271-297

Holmes RL (1983) Computer-assisted quality control in tree-ring dating and measurement. Tree-Ring Bull 43:69-78
Li WY (1991) Relationships between pollen and plant of the Abies fargesii forest and its succession in the Shennongjia mountain. Acta Geograph Sin 46(2):186-194

Liu HB, Shao XM (2000) Reconstruction of early-spring temperature at zhenan from 1755 using tree ring chronology. J Meteor Res 58(2): 223-233

Liu Y, An ZS, Linderholm HW, Chen DL, Song HM, Cai QF, Sun JY, Tian H (2009) Annual temperatures during the last 2485 years in the mid-eastern Tibetan plateau inferred from tree rings. Sci China Ser D Earth Sci 52(3):348-359

Ljungqvist FC (2010) A new reconstruction of temperature variability in the extra-tropical northern hemisphere during the last two millennia. Geogr Ann A 92(3):339-351

Massaccesi G, Roig FA, Martínez Pastur GJ, Barrera MD (2008) Growth patterns of nothofagus pumilio trees along altitudinal gradients in Tierra del Fuego, Argentina. Trees-Struct Funct 22:245-255

Melvin TM, Briffa KR (2008) A "signal-free" approach to dendroclimatic standardisation. Dendrochronologia 26(2):71-86

Melvin TM, Briffa KR (2014) CRUST: software for the implementation of regional chronology standardisation: part 1. Signal-free RCS. Dendrochronologia 32(1):7-20

Moberg A, Sonechkin DM, Holmgren K, Datsenko NM, Karlén W (2005) Highly variable northern hemisphere temperatures reconstructed from low-and high-resolution proxy data. Nature 433(7026):613-617

Rinn F (2003) TSAP-Win: time series analysis and presentation for dendrochronology and related applications. Version 4.64 User reference

Rydval M, Larsson L-Å, McGlynn L, Gunnarson B, Loader N, Young G, Wilson R (2014) Blue intensity for dendroclimatology: should we have the blues? Experiments from Scotland. Dendrochronologia 32(3):191-204

Salzer MW, Kipfmueller KF (2005) Reconstructed temperature and precipitation on a millennial timescale from tree-rings in the southern Colorado plateau, USA. Clim Chang 70(3):465-487

Shao X, Xu Y, Yin Z-Y, Liang E, Zhu H, Wang S (2010) Climatic implications of a 3585-year tree-ring width chronology from the northeastern Qinghai-Tibetan plateau. Quat Sci Rev 29(17):2111-2122

Shi JF, Cook ER, Lu HY, Li JB, Wright WE, Li SF (2010) Tree-ring based winter temperature reconstruction for the lower reaches of the Yangtze river in southeast China. Clim Res 41(2):169-175

Wu CF (1986) Jackknife, bootstrap and other resampling methods in regression analysis. Ann Stat 14(4):1261-1295

Yamaguchi DK (1991) A simple method for cross-dating increment cores from living trees. Can J For Res 21(3):414-416

Yang B, Qin C, Wang JL, He MH, Melvin TM, Osborn TJ, Briffa KR (2014) A 3,500-year tree-ring record of annual precipitation on the northeastern tibetan plateau. P Natl Acad Sci USA 111(8):2903-2908

Yonenobu H, Eckstein D (2006) Reconstruction of early spring temperature for central Japan from the tree-ring widths of Hinoki cypress and its verification by other proxy records. Geophys Res Lett 33(10): $1-5$

Zhao C, Chen W, Tian Z, Xie Z (2005) Altitudinal pattern of plant species diversity in Shennongiia mountains, central China. J Integr Plant Biol 47(12):1431-1449

Zheng Y, Zhang Y, Shao X, Yin Z-Y, Zhang J (2012) Temperature variability inferred from tree-ring widths in the Dabie mountains of subtropical central China. Trees-Struct Funct 26(6):1887-1894

Zhu HF, Fang XQ, Shao XM, Yin ZY (2009) Tree ring-based FebruaryApril temperature reconstruction for Changbai mountain in northeast China and its implication for east Asian winter monsoon. Clim Past 5(4):661-666

Zhu HF, Shao XM, Yin ZY, Huang L (2011) Early summer temperature reconstruction in the eastern Tibetan plateau since ad 1440 using tree-ring width of Sabina tibetica. Theor Appl Climatol 106(1-2): $45-53$ 